\title{
AULAS PRÁTICAS DE CIÊNCIAS NATURAIS: O USO DO LABORATÓRIO E A FORMAÇÃO DOCENTE
}

\author{
PRACTICAL CLASSES IN NATURAL SCIENCES: THE USE OF \\ THE LABORATORY AND TEACHING TRAINING
}

\section{CLASES PRÁCTICAS EN CIENCIAS NATURALES: EL USO DE LABORATORIO Y EL ENTRENAMIENTO DOCENTE}

\author{
Elânia Francisca da Silva ${ }^{1}$ \\ https://orcid.org/0000-0003-3075-7111 \\ Raimundo Nonato Costa Ferreira ${ }^{2}$ \\ https://orcid.org/0000-0001-6260-6807 \\ Elaine de Jesus Souza ${ }^{3}$ \\ http://orcid.org/0000-0003-3931-0025

\footnotetext{
${ }^{1}$ Universidade Federal do Cariri, Brejo Santo, Ceará - Brasil. E-mail: elania964@ gmail.com.

${ }^{2}$ Universidade Federal do Cariri, Brejo Santo, Ceará - Brasil. E-mail: nonato.ferreira@ufca.edu.br.

${ }^{3}$ Universidade Federal do Cariri, Brejo Santo, Ceará - Brasil. E-mail: elaine.souza@ufca.edu.br.
}

\section{Resumo}

As Ciências Naturais (CNs) são formadas por disciplinas de essência experimental, portanto, para que o processo de ensino e aprendizagem seja efetivo, faz-se necessário o uso de aulas práticas realizadas em laboratório. Este estudo, que tem como objetivo avaliar a utilização de laboratórios pelos/as docentes de $\mathrm{CN}$ do ensino fundamental - anos finais, está relacionado com a formação acadêmica, enfocando a importância da realização de aulas práticas. É uma pesquisa de abordagem qualitativa, com aplicação de um questionário contemplando, ao todo, 24 professores/as dos municípios de Abaiara, Brejo Santo e Milagres que lecionam em escolas da rede pública municipal, nos anos finais do ensino fundamental. Dessa forma, foi possível observar, entre os/as entrevistados/as, que $50 \%$ são formados nas áreas que compreendem as CNs, porém é perceptível que professores/as que não são de áreas afins às CNs ministram aulas nessa disciplina. Também foi possível observar que, na região estudada, o/a docente, mesmo formado/a dentro da área de $\mathrm{CN}$, considera sua formação acadêmica insuficiente para conduzir aulas práticas de laboratório. As dificuldades encontradas pelos/as docentes perpassam sua formação e também estão atreladas à falta de estrutura física e à localização das escolas onde lecionam.

Palavras-chave: Aulas Práticas. Ensino de Ciências. Formação Docente. 


\begin{abstract}
The Natural Sciences (NS) are formed by disciplines of experimental essence, therefore, for the teaching and learning process to be effective, it is necessary to use practical classes held in the laboratory. This study aimed to evaluate how the use of laboratories by the teachers of $N S$ in the final years of elementary school is related to their academic training, focusing on the importance of conducting practical classes. The present work was carried out through a qualitative research, with the application of a questionnaire to 24 teachers in the municipalities of Abaiara, Brejo Santo and Milagres, who teach in elementary schools in the final years of the municipal public system. Thus, it was possible to observe among the interviewees: $50 \%$ are trained in the areas that comprise the NSs. However, it is noticeable that teachers who are not related to the NS teach classes in this discipline. It was also possible to observe that in the studied region, the teacher, even trained within the NS area, considered his academic education insufficient to conduct practical laboratory classes. The difficulties encountered by the teachers permeate their training and are also linked to the lack of physical structure and the location of the schools where they teach.
\end{abstract}

Keywords: Practical Classes. Science Teaching. Teacher Training.

\title{
Resumen
}

Las Ciencias Naturales (CN) forman parte de disciplinas de carácter experimental, por lo tanto, para que el proceso de enseñanza y aprendizaje sea efectivo, es necesario utilizar clases prácticas realizadas en el laboratorio. Este estudio, lo cual tiene como objetivo evaluar el uso de laboratorios por los profesores de $C N$ de los últimos años de la escuela primaria, se relaciona con su entrenamiento académico, enfocándose en la importancia de la realización de clases prácticas. Se trata de una investigación de abordaje cualitativa, con la aplicación de un cuestionario que abarca un total de 24 docentes de los municipios de Abaiara, Brejo Santo y Milagres que ensenãn en los últimos años de escuelas primarias del sistema público municipal. Así, se pudo observar entre los entrevistados, que el $50 \%$ tienen capacitación en las áreas que componen las CNs, sin embargo, se nota que los maestros que no forman parte de áreas afines a las CNs enseñan esa disciplina. También se pudo observar que, en la región estudiada, el docente, incluso capacitado en el área de CN, considera su formación académica insuficiente para realizar clases prácticas de laboratorio. Las dificultades encontradas por los docentes atravesan su capacitación y también están atadas a la falta de estructura física y a la ubicación de las escuelas donde enseñan.

Palabras clave: Clases Prácticas. Enseñanza de las Ciencias. Capacitación Docente.

\section{Introdução}

As Ciências Naturais (CNs) são essencialmente formadas por disciplinas experimentais, portanto são mais bem compreendidas quando o processo de ensino e aprendizagem das áreas que a compõem é efetivado utilizando-se atividades práticas. Tais aulas visam a estreitar a relação entre teoria e prática, sendo necessária uma formação 
acadêmica dos professores que englobe aulas laboratoriais associada a uma disponibilidade escolar dos laboratórios.

Isso, no entanto, torna-se desafiador, uma vez que muitas escolas do ensino fundamental - anos finais não possuem laboratórios de $\mathrm{CN}$ e as que dispõem desse espaço não fazem uso dele, o que afeta diretamente a qualidade do ensino e da aprendizagem dessa disciplina. Outro desafio para os professores utilizarem esse recurso está em sua formação, pois, em alguns casos, falta capacitação para o manuseio dos equipamentos de laboratório, o que se torna um empecilho para o docente. Conforme afirmam Santos et al. (2016, p. 235), "o não uso de atividades experimentais acaba acontecendo pelo fato de docentes não terem formação, conhecimento e competência para a utilização destas para desenvolvê-las".

De fato, isso é um problema, mas não indica que seja apenas falta de interesse do docente, sendo também de responsabilidade da escola buscar meios para solucionar essa problemática. As escolas devem destinar espaços físicos aos laboratórios necessários à proposta pedagógica, promovendo a aquisição de conhecimento e melhorando o ensino, como salienta Cruz (2007). Além disso, faz-se necessário que as aulas práticas experimentais façam parte da vida do estudante, e não sejam algo extraordinário que só sirva para sair da sala de aula. É cabível à instituição escolar e à Secretaria de Educação buscar a formação continuada para esses professores, principalmente quando a sua formação foi deficiente em termos do uso de laboratórios, e a manutenção regular dos equipamentos, posto que não basta apenas possuir a estrutura; é necessário cuidar para que ela funcione bem.

A CN se configura como um vasto campo de ensino e aprendizagem que permite inúmeros tipos de aulas práticas mediante o uso de materiais do dia a dia, de laboratórios, aula ao ar livre e demais métodos. Assim, questionamo-nos: qual a relação entre a formação dos professores e o uso (ou não) de laboratórios de CN para aulas práticas? Ou de que modo outros fatores dificultam ou encorajam a utilização de laboratórios para aulas práticas? Todas essas indagações são pertinentes na vida acadêmica do professor.

Diante de todos os aspectos aqui apresentados sobre essa problemática com elementos essenciais para a discussão, essa pesquisa se propõe a investigar, nos municípios de Abaiara, Brejo Santo e Milagres, do Cariri cearense, se os fatores relacionados com o uso ou não dos laboratórios de $\mathrm{CN}$ estão atrelados à formação do professor ou em conjunto com outros fatores com o objetivo de analisar como (ou de que modos) a utilização de laboratórios, para 
aulas práticas, pelos professores de $\mathrm{CN}$ do ensino fundamental -anos finais estaria relacionada com a formação acadêmica desses docentes.

\section{Formação dos professores e o laboratório de Ciências Naturais}

No campo acadêmico, a discussão em relação à formação dos professores se tornou recorrente, visto que, por meio da universidade, ocorre apenas sua capacitação inicial, sendo a base de sua jornada na vida acadêmica. É necessária, no entanto, uma formação contínua que perpasse a graduação. Para Berezuki, Obara e Silva (2009), faz parte da formação do licenciando em $\mathrm{CN}$ aprender a desenvolver e diferenciar os trabalhos prático, experimental, laboratorial e de campo, sendo ele capaz de levar uma educação científica de qualidade aos alunos. Também é importante conhecer bem a matéria a ser ensinada, preparar-se, saber como preparar a turma para essa prática e como ligá-la ao senso comum dos alunos, pois terão sua curiosidade aguçada e irão buscar meios de associá-la ao seu dia a dia. Tomando por base o que diz Furmam (2009, p. 7):

\footnotetext{
Ensinar Ciências Naturais é um privilégio de grande responsabilidade. Temos o papel de orientar nossos alunos para o conhecimento desse mundo novo que se abre diante deles[...] será nossa tarefa aproveitar a curiosidade que todos os alunos trazem para a escola como plataforma sobre a qual estabelecer as bases do pensamento científico e desenvolver o prazer por continuar aprendendo.
}

$\mathrm{O}$ processo de ensino e aprendizagem que exacerba a curiosidade e a vontade de aprender é o que torna o ensino prazeroso tanto para os discentes como para os docentes, sendo a base da aprendizagem o acordar para o saber científico. Atualmente, entretanto, as licenciaturas ainda são voltadas para aulas ministradas de forma teórica, o que dificulta a aprendizagem dos discentes quanto a como utilizar as aulas práticas, enfraquecendo a relação teórico-prática e permitindo aos mesmos terem dúvidas sobre sua metodologia de ensino. $\mathrm{O}$ fato de os cursos de formação não articularem a teoria à prática acarreta uma insegurança em seus licenciados no desempenho da docência em escolas públicas e privadas brasileiras (VIEGAS; CRUZ e MENDES 2015).

Seguindo a linha de raciocínio dos autores, observa-se a fragilidade das licenciaturas, o que permite aos seus licenciados terem dúvidas sobre seus métodos pedagógicos e como 
associar a teoria à prática, demonstrando, assim, o problema que o futuro professor irá encontrar em sala de aula. De todo modo, a formação de um docente em CN leva a um vasto campo de possibilidades de pesquisas, práticas, êxitos e problemas, o que possibilita construir um perfil docente fundamentado no que foi aprendido durante a graduação (MARANDINO, 2009).

É notório que, durante sua formação, essa relação entre teoria e prática faz-se necessária para conduzir o discente a pesquisar e desenvolver métodos de aperfeiçoamento entre o ensino e a pesquisa e buscar metodologias que facilitem seu trabalho. Da mesma forma, auxilia o aluno com a aprendizagem do conteúdo curricular, permitindo-lhe também utilizar esses conhecimentos no ensino médio, visando a compreender a Química, a Física e a Biologia. Desse modo, o futuro professor torna-se um docente hábil a trabalhar de forma interdisciplinar, sendo essa uma demanda não só de cunho acadêmico e científico, mas também social. Para Pierson e Neves (2001) é imprescindível pensar em uma formação de professores de Ciências com uma base para lidar com as necessidades educacionais de uma sociedade em transformação e que reflete sobre novas competências de atuação.

Uma das metodologias disponíveis para suprir essas necessidades é a utilização de laboratórios de $\mathrm{CN}$ para aulas práticas. Esse método permite fazer a Ciência com as próprias mãos, já que, em uma aula de laboratório bem planejada e executada, o estudante pode entender como observar fenômenos naturais e elaborar hipóteses científicas. $\mathrm{O}$ desenvolvimento dessa capacidade de observação é muito importante para a $\mathrm{CN}$, pois contribui para o enriquecimento da relação entre teoria e prática por meio da observação do experimento. Tudo isso converge com o que relatam Villani e Pacca (1997, p. 1): “A finalidade do ensino de ciências é aproximar o estudante do conhecimento científico continuamente reformulado e aumentado, e a atuação do professor deve ser coerente com este propósito". O uso do laboratório visa a estreitar os laços com a teoria.

O laboratório é um campo vasto para o desenvolvimento da autonomia do aluno, permitindo testar suas ideias sobre determinados fenômenos e, assim, levantar hipóteses. As atividades experimentais são essenciais à ciência e sua averiguação é a comprovação da teoria. Em seus depoimentos, os alunos costumam atribuir à experimentação um caráter motivador, lúdico, essencialmente vinculado aos sentidos, o que nos faz refletir como serão as futuras formações desses profissionais e se, como enfatiza Mello (2000), no futuro, o 
professor terá a capacidade de fazer seus alunos relacionarem a teoria com a prática, despertando a análise e a compreensão dos fatos da vida real.

\section{Laboratório de Ciências Naturais no ensino fundamental - anos}

\section{finais}

Não são recentes os estudos sobre as atividades experimentais no Brasil. Esses experimentos começaram a se expandir na década de 1960, buscando resultados mais eficazes na educação. Segundo Rodrigues e Borges (2008), traduzir projetos norte-americanos para o português foi a grande jogada para se ter, até os tempos atuais, projetos científicos na educação brasileira. Esses estudos contribuíram para uma reformulação educacional usandose aulas práticas laboratoriais. $\mathrm{O}$ ensino por meio de metodologias alternativas é mais uma ação que complementa a prática cotidiana de professores do que um abandono de práticas convencionais (YAMAZAKI E YAMAZAKI, 2006). Assim, ao levarmos em consideração a realidade na qual esses alunos se encontram inseridos, em uma era digital em que o acesso à internet é cada vez mais comum, as metodologias que envolvam a utilização da internet poderão ser benéficas para o processo de ensino e aprendizagem dos alunos.

Damasceno (2016) nos lembra que, durante o processo de ensino de Ciências, as escolas negligenciam a utilização do laboratório por diversos motivos - falta de tempo, materiais, profissionais com capacidade de manuseá-los -, esquecendo-se de que os laboratórios despertam no aluno seu senso investigativo, fazendo que ele reflita, julgue, colabore com o colega, seja mais participativo e atento ao conteúdo. As aulas práticas não substituem as teóricas, mas servem como complementação da teoria, havendo coerência entre o contexto proposto e a prática que será aplicada. Tendo isso em vista, o educando tem uma visão mais ampla sobre o assunto, tornando a aprendizagem de $\mathrm{CN}$ mais atrativa (AFONSO; BONAPAZ; SEVERO, 2014). Segundo Rossasi e Polinarski (2015, p. 11), tais aulas "permitem aos educandos um contato direto com os fenômenos, manuseio de equipamentos e observação dos organismos, desafiando, assim, sua imaginação e raciocínio".

De acordo com Krasilchik (2008), existem quatro graus de liberdade para o bom desenvolvimento de uma aula em laboratório: 1) o docente oferece um problema, demonstra como resolvê-lo e apresenta os resultados esperados; 2) os alunos recebem o problema e as instruções de como proceder; 3) os alunos são livres para escolher o procedimento, coletar 
dados e interpretá-los; e 4) é permitido ao discente identificar, investigar, planejar, executar o experimento e chegar às interpretações dos resultados. Com essa liberdade o aluno passará a enxergar o objeto ou fenômeno de estudo como um todo, sentindo-se capaz de concretizar os estudos teóricos repassados pelo professor e obtendo como resultado a construção de conhecimento sobre os estudos realizados. Esse fato está atrelado diretamente ao estímulo da curiosidade investigativa dos discentes. Ao longo do andamento do ensino fundamental anos finais, o aluno tende a desenvolver seu senso crítico e social, podendo utilizar conhecimentos adquiridos na escola para transformar o meio em que convive, de forma que uma boa educação científica irá contribuir para seus valores éticos.

\section{Caminhos metodológicos}

O presente trabalho foi realizado em 19 escolas da rede pública municipal, no ensino fundamental -anos finais, de três municípios do Cariri cearense: Abaiara, Brejo Santo e Milagres, com um total de 24 participantes, durante o mês de maio de 2019. Esses municípios foram escolhidos devido à proximidade de um novo curso de licenciatura que começou a receber docentes recém-formados nessa área.

A pesquisa é qualitativa para a investigação que busca "intervir em uma situação insatisfatória, mudar condições percebidas como transformáveis, onde pesquisador e pesquisados assumem, voluntariamente, uma posição reativa" (CHIZZOTTI, 2014, p. 89).

Foi aplicado um questionário com perguntas abertas sobre a problemática em questão, em que os docentes relaram sua formação, dificuldades no uso dos laboratórios e no ensino de CN. Em algumas das questões, foi solicitado ao docente que se atribuísse uma nota de um a cinco, considerando um "pouco suficiente" e cinco "suficiência ótima" em relação ao tema da questão.

Quanto aos docentes do município de Abaiara houve um contato prévio com a direção das escolas envolvidas para que a aplicação do questionário fosse autorizada no âmbito escolar. Para os professores dos municípios de Brejo Santo e Milagres a aplicação do questionário ocorreu durante um curso de formação continuada ministrado a professores de $\mathrm{CN}$, tendo sido realizado um contato prévio com o formador e, em seguida, com os professores. Caracterizaram-se os docentes por meio de questionamentos sobre sua formação acadêmica, carga horária, opiniões sobre a suficiência de suas formações durante a graduação 
para uso de laboratório, se a escola onde lecionam possui laboratório, que tipo, os equipamentos e vidrarias e sobre os conteúdos ministrados em laboratório. Para facilitar a interpretação dos resultados, os docentes foram agregados formando três grupos de acordo com as respostas dos questionários: 1) formados em Biologia; 2) formados em Ciências Naturais; e 3) na área de exatas. Os dados obtidos foram analisados e expressos por meio de gráficos e tabelas.

\section{Resultados e discussões}

Nos três municípios abrangidos neste estudo, foram aplicados questionários a cinco professores no município de Abaiara, de três escolas diferentes, todas da zona urbana. Em Brejo Santo, obteve-se o total de 15 professores que lecionam em 12 escolas, incluindo oito na zona rural e quatro na zona urbana. Em Milagres, foram aplicados a quatro docentes de quatro escolas diferentes da zona urbana. Cada professor reservou cerca de 10 minutos para responder ao questionário.

\subsection{Formação acadêmica dos docentes avaliados}

A partir dos questionários aplicados foi possível observar que a maioria dos professores do ensino de $\mathrm{CN}$ é graduada em Biologia, seguida pela formação em $\mathrm{CN}$, Matemática, Física e Engenharia Civil (Gráfico 1). Foi observado também que, dos 24 docentes que responderam ao questionário, um possui apenas bacharelado. 
Gráfico 1 - Perfil da formação dos docentes de Ciências Naturais nos três municípios.

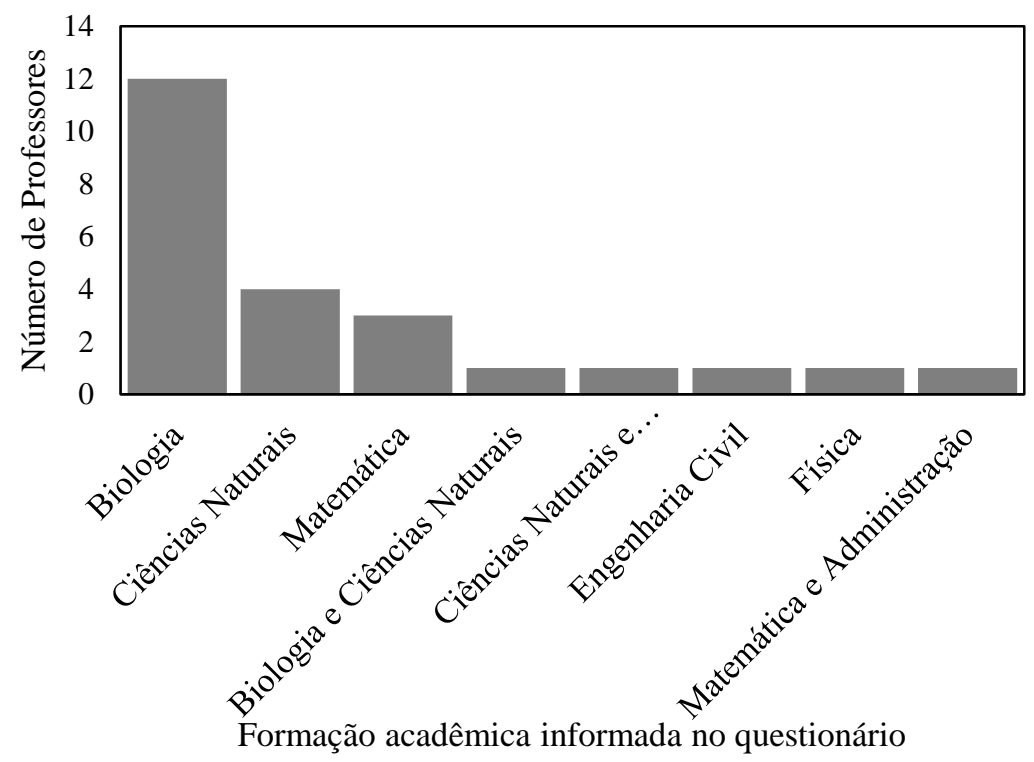

Fonte: Dados da pesquisa, 2019.

Dos professores entrevistados, 12 disseram ser formados em Biologia e quatro em $\mathrm{CN}$, porém observou-se que três deles são formados em Matemática, um em Engenharia Civil, um em Física e outro possui graduação tanto em Matemática quanto em Administração. Como salienta Assolini (2017, p. 1), "na ausência de professores com formação específica, mobilizam-se aqueles docentes com formação em áreas afins", como, por exemplo, no caso da Biologia, cuja disciplina afim é a Química. Essa demanda, porém, não justifica algumas situações observadas neste trabalho, como professores de Matemática ministrando aula de $\mathrm{CN}$ (Gráfico 1). A não formação nessa área não contribui para a aprendizagem de Ciências, pois o docente não formado na área tende a ter mais dificuldade para se aprofundar nos conhecimentos de $\mathrm{CN}$. Os docentes que participaram da pesquisa se formaram entre os anos de 1999 e 2019, como demonstra o Gráfico 2. 
Gráfico 2 - Número de docentes de Ciências Naturais nos três municípios, de acordo com os anos de sua formação.

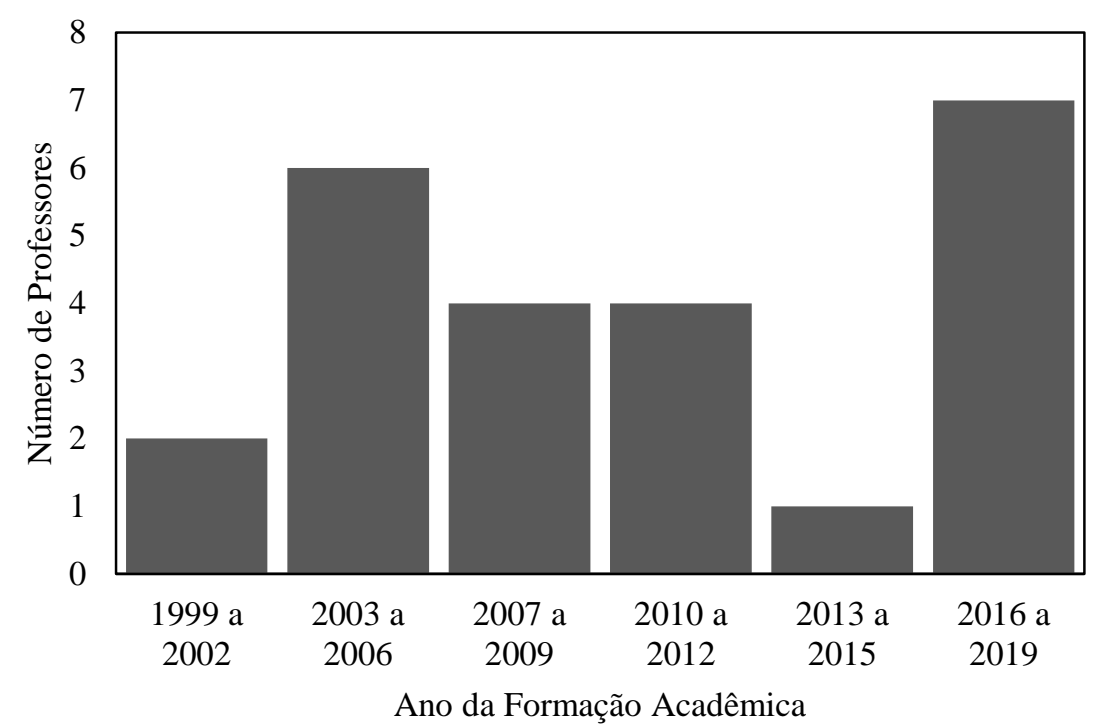

Fonte: Dados da pesquisa, 2019.

Percebe-se que, de 2016 a 2019, houve um aumento de professores formados em relação aos outros anos, com sete formados. Esse aumento de docentes nos municípios de Abaiara, Brejo Santo e Milagres pode estar associado à presença do novo curso de Licenciatura em $\mathrm{CN}$ e Matemática recém-implantado na região do Cariri cearense. Quando solicitados a atribuir uma nota de um a cinco com relação à contribuição da estrutura fornecida pela instituição em que se formou para a formação prática no ensino de $\mathrm{CN}$, os docentes com formação em $\mathrm{CN}$ tiveram a menor média da nota (Gráfico 3). Podemos perceber que, mesmo os recém-formados, não se sentem aptos a utilizar um laboratório de CN. Essa observação corrobora a de Santos et al. (2016, p. 227), que afirmam que "uma formação de docentes que estimule e prepare todos esses saberes, futuramente, obterá resultados construtivistas e um ensino significativo".

Observou-se também que, entre os professores formados nas três áreas analisadas neste estudo, os de $\mathrm{CN}$ consideraram que a estrutura de laboratório fornecida pela instituição onde se formaram foi insuficiente para auxiliá-los a desenvolver habilidades práticas na manipulação de equipamentos, atribuindo a essa questão a nota média próxima de 1,5, como evidencia o Gráfico 3. 
Gráfico 3 - Percepção dos professores de Ciências Naturais com relação à contribuição da estrutura física da instituição formadora para a sua habilidade em ministrar aulas práticas de laboratório.

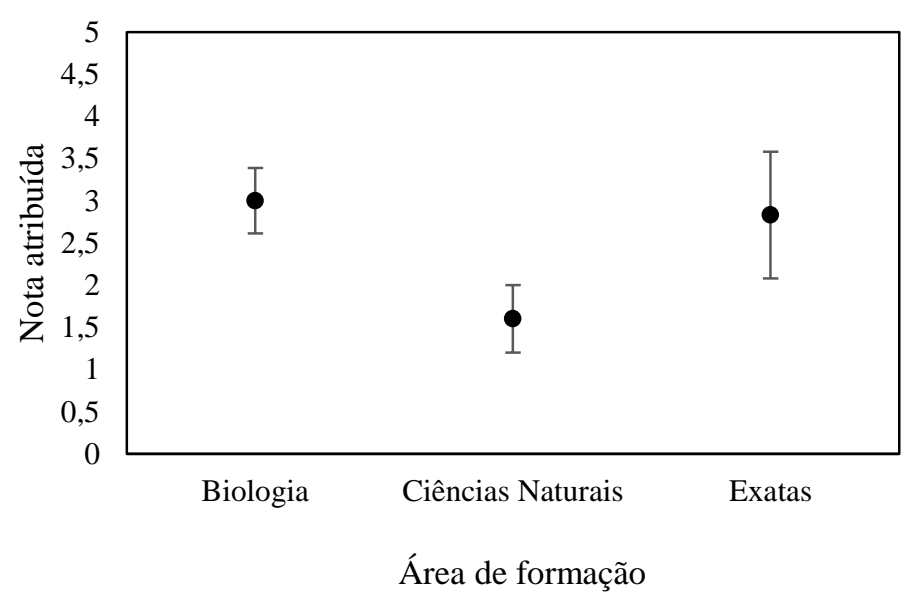

Fonte: Dados da pesquisa, 2019.

Andrade e Costa (2016, p. 209) analisam que "muitos professores de Ciências Naturais têm uma formação inicial deficiente, abordando as aulas práticas laboratoriais de forma simplista e sem o preparo didático para lidar com o ensino básico". Esses dados demonstram que as instituições de formação desses docentes foram deficientes em relação à estrutura, o que vem a colaborar para sua insegurança em ministrar aulas laboratoriais.

Um dos motivos que pode ter contribuído para essa percepção de pouca prática na formação pode estar relacionado com o fato de que 19 desses docentes, durante a sua formação, não participaram como bolsistas ou voluntários de algum programa de extensão, iniciação à docência ou científica. Entre os 24 entrevistados, apenas dois participaram do Programa Institucional de Bolsas de Iniciação Científica (PIBIC), dois de programa de extensão e um do Programa Institucional de Bolsas de Iniciação à Docência (PIBID). Assim, percebe-se que as notas atribuídas no Gráfico 3 estão relacionadas também com a segurança que esses docentes têm demonstrado no Gráfico 4, em ministrar aulas práticas. Ou seja, observa-se uma relação entre a falta de estrutura física da instituição de formação e a insegurança em ministrar aulas em laboratório. 
Gráfico 4 - Percepção dos docentes quanto à própria formação prática. Notas próximas de cinco indicam muita segurança e, de um, pouca segurança.

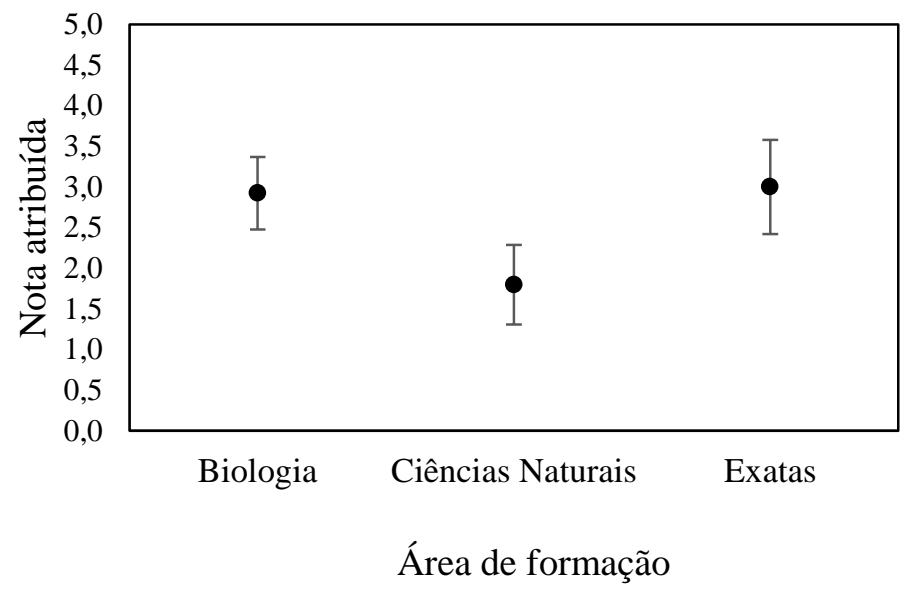

Fonte: Dados da pesquisa, 2019.

O PIBIC promove a formação de futuros pesquisadores, estimulando-os a desenvolverem uma pesquisa íntegra e coerente com seus estudos, ingressar em um mestrado e, posteriormente, no doutorado (SOUZA; ONAKA, 2015, p. 24451). Ao ingressar nesse tipo de programa, o futuro docente passa a obter um conhecimento científico mais específico em determinada área, o que lhe possibilita não só estabelecer sua projeção para o futuro, como um mestrado e, posteriormente, um doutorado, mas também um melhor desempenho como licenciado/a no dia a dia escolar. Em relação ao PIBID, os mesmos autores ressaltam que esse programa auxilia tanto o acadêmico como as instituições que recebem o bolsista, que busca trabalhar de forma lúdica a temática do programa, ou seja, contribui para com a universidade, o/a docente, a escola, o professor orientador e os alunos, transformando todas essas áreas.

Diante do exposto, é valido salientar o papel da formação docente na graduação, pois os discentes são estimulados a participar desses programas, porém alguns fatores podem impedir sua participação, como falta de tempo, auxílio financeiro, localização e até mesmo falta de interesse. Soares (2014) corrobora isso enfatizando que tais dificuldades não afetam somente a participação do aluno em programas estudantis, mas também a sua permanência na universidade, daí a necessidade de políticas públicas voltadas para garantir a permanência desses discentes em seus almejados cursos. Assim, uma formação na qual o ingresso se sinta amparado tanto pelo governo como pela instituição permitirá ao mesmo um amparo para burlar alguns obstáculos que tendem a aparecer durante sua graduação. Sua participação 
nesses programas, todavia, é opcional, não sendo pré-requisito para a sua graduação, o que os limita àqueles que têm tempo para se dedicar a tais atividades e/ou não precisam trabalhar durante a sua graduação.

\subsection{Regime de trabalho e atuação docente}

Com relação ao número de instituições em que cada docente leciona, obteve-se que 14 dizem atuar em apenas uma escola; seis, em duas escolas; dois, em três escolas; e outros dois lecionavam em oito instituições. Quatorze docentes informaram que sua carga horária tem suficiência média para planejar aulas em laboratório, enquanto quatro a consideraram insuficiente e oito, muito suficiente, sendo semelhantes as notas atribuídas em relação à suficiência de carga horária por docentes de cada área (nota média por área: Biologia 3,10 \pm 0,35; CN 2,6 $\pm 0,40$ e exatas 3,3 \pm 0,42). A carga horária média, por área, dos docentes entrevistados neste estudo pode ser observada no Gráfico 5.

Gráfico 5 - Carga horária média dos docentes no ensino fundamental - anos finais, de acordo com a área de formação.

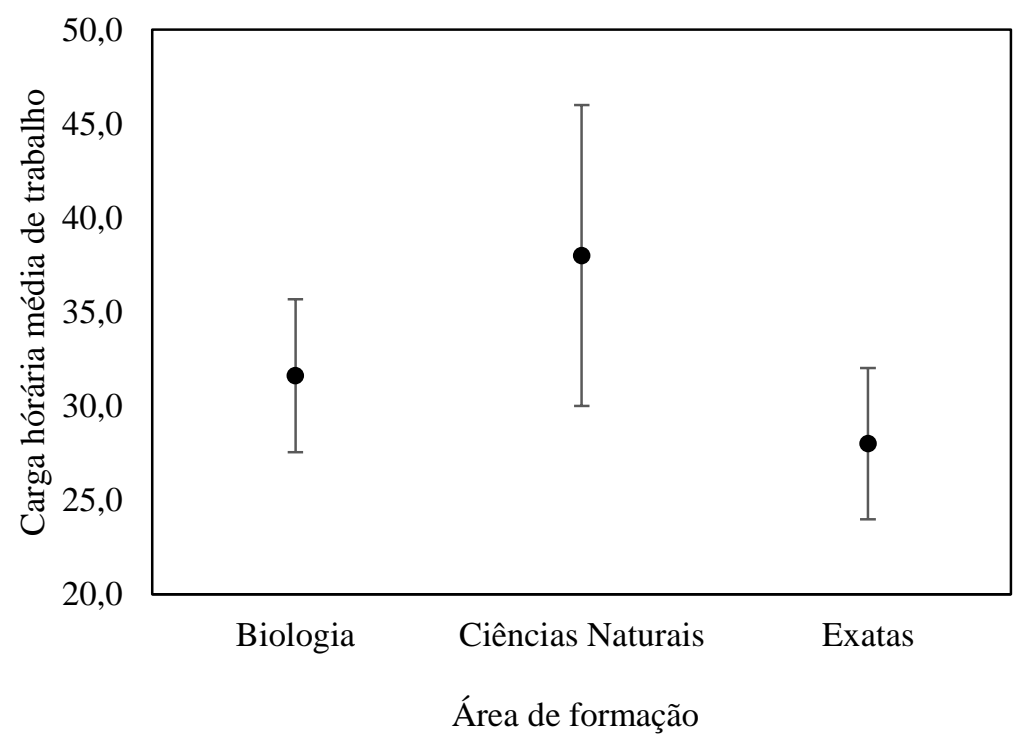

Fonte: Dados da pesquisa, 2019. 
Ao se observarem esses dados, percebe-se que a variação nas notas atribuídas pelos professores de $\mathrm{CN}$ para suficiência de sua carga horária relaciona-se com a quantidade de instituições que lecionam e a carga horária de trabalho. Assim, a pouca ênfase em aulas práticas pode também estar atrelada a outro fator, como a falta de um laboratório na instituição onde lecionam. Como salientam Andrade e Costa (2016, p. 209), "a inexistência de laboratório é um dos fatores mais citados entre os trabalhos que buscam verificar os empecilhos para a realização de aulas práticas”.

\subsection{Estruturas físicas de laboratórios de Ciências nas instituições onde os} docentes lecionam

Com relação à estrutura de cada escola, 23 dos docentes responderam que as escolas onde lecionam não possuem laboratórios na área de CN. Apenas um afirmou que a sua escola, localizada na zona urbana, tem um laboratório de Ciências e que faz uso dele somente duas vezes por semestre. Em relação aos outros tipos de laboratório, um professor respondeu que a instituição tem um laboratório de redação e outro, um laboratório de informática. Esses professores afirmaram que, na ausência de laboratórios, elaboram aulas expositivas em sala. Um dos professores destacou que "a prática é utilizada através de demonstrações simples, com materiais de fácil acesso e comuns à realidade dos alunos, para demonstrar determinados fenômenos"; outros disseram que usam recursos audiovisuais, sucatas, materiais reciclados e de baixo custo (Tabela 1).

Souza (2007, p. 111) diz que "os recursos didáticos não devem ser utilizados de qualquer jeito, o professor deve dispor de tempo e conhecimento para planejar e utilizá-los de maneira que se possa alcançar o objetivo proposto pela disciplina”. Sendo assim, é necessário um espaço adequado para essas atividades práticas. Os professores relataram que lecionam em 19 escolas, sendo que alguns nas mesmas escolas. No total, 11 dessas instituições estão localizadas na zona urbana e oito na zona rural. O fato de a zona urbana possuir mais escolas demonstra que pode estar havendo um maior investimento nas escolas localizadas nas sedes dos municípios.

Corrobora-se, portanto, que as dificuldades encontradas por professores da zona rural são maiores em relação à zona urbana em questão de estrutura física, investimentos e incentivo da gestão escolar. Relacionando com relatos de um estudo realizado nos estados de 
Pernambuco e São Paulo por Pontili e Kassouf (2007), a área rural tem indicativos educacionais de alta precariedade em comparação com a urbana, pois ocorre uma alta rotatividade de professores, assim como escassez de laboratórios, bibliotecas, além de o ambiente físico ser precário. Esse relato mostra o quanto é frágil, dependendo da região, a educação em relação à qualidade do ambiente escolar e o quanto os fatores expostos anteriormente dificultam o desenvolvimento do trabalho escolar, e essa falta de disponibilidade de laboratório aumenta esses indicadores educacionais.

Apenas três professores relataram que as escolas onde lecionam possuem microscópio. Um listou estereomicroscópio, bico de Bunsen e estufa, e dois descreveram que possuem medidor de $\mathrm{pH}$ e modelos anatômicos. A mesma quantidade de professores narrou que desconhece esses equipamentos. Dezoito afirmaram que as escolas não possuem esses equipamentos (Tabela 1).

Tabela 1 - Respostas dos professores a respeito dos equipamentos presentes no laboratório de Ciências Naturais nas escolas onde lecionam.

\begin{tabular}{l|l}
\hline \multicolumn{1}{c}{ O(s) laboratório(s) de Ciências a sua instituição possui(em) os seguintes equipamentos? } \\
\hline \multicolumn{1}{c}{ Equipamentos } & \multicolumn{1}{c}{ Quantidade de professores } \\
\hline Microscópio & 3 \\
\hline Estereomicroscópio & 1 \\
\hline Bico de Bunsen & 1 \\
\hline Modelos anatômicos & 2 \\
\hline Estufa & 1 \\
\hline Medidor de pH & 2 \\
\hline Desconheço esses equipamentos & 2 \\
\hline Nenhum & 18 \\
\hline
\end{tabular}

Fonte: Dados da pesquisa, 2019.

Com relação à vidraria, 21 docentes relataram que, na escola onde lecionam, não há vidraria; dois afirmaram que desconhecem esses equipamentos e apenas um disse que a escola onde leciona possui vidrarias como placa de Petri, tubo de ensaio, balão de fundo chato, 
lâminas para microscopia, proveta, balão de destilação, béquer, balão de Erlenmeyer, termômetro. Vidrarias são importantes instrumentos na realização de aulas práticas. Confeccionadas em vidro transparente, resistente ao calor e inerte, são utilizadas em análises e experimentos científicos, principalmente nas disciplinas de Química e Biologia (GAVETTI, 2013). Como podemos constatar, a maioria dos professores disse que as escolas não possuem nem equipamentos de laboratório, nem vidrarias, o que é um fato preocupante no desenvolvimento de atividades práticas, visto que as aulas teóricas ocupam boa parte da carga horária e aulas práticas precisam da disponibilidade de materiais, como microscópio e reagentes, espaço físico e outros (BEREZUK; INADA, 2010, p. 208), cuja falta prejudica o desempenho dessas atividades.

Uma vez que uma das funções do laboratório é promover o acesso dos discentes a materiais e equipamentos que, se manipulados com segurança, serão pertinentes para a construção da sua aprendizagem (KOREN; BERTOLDO, 2013), disponibilizar aos alunos essa interação com a prática é conduzi-los a obterem soluções para problemas do seu cotidiano, consentindo-lhes relacionar a teoria com a prática e o seu dia a dia, desenvolvendo, assim, um gosto especial pela área científica. É observado, no entanto, que, mesmo que a instituição formadora dos docentes fornecesse formação ideal que lhes desse segurança para planejar e executar aulas práticas, a estrutura das escolas ainda não permitiria a execução dessas aulas.

Em relação aos conteúdos ministrados utilizando-se laboratórios, observou-se que, dos 24 professores entrevistados, somente quatro responderam, o que é um número considerado pequeno em relação à quantidade de docentes que se omitiram a responder (20), o que demonstra o quanto eles estão ministrando somente aulas teóricas (Tabela 3). 
Tabela 3 - Resultados obtidos em relação ao conteúdo da disciplina de CN ministrados em laboratório.

\begin{tabular}{l|l}
\hline \multicolumn{2}{c}{ Qual conteúdo da disciplina de Ciências Naturais você ministra utilizando o laboratório? } \\
\hline Não respondeu & 10 professores \\
\hline Nenhum & 10 professores \\
\hline Separação de misturas, indicadores ácidos e base, & 01 professor \\
reações químicas, óptica, propriedades da matéria & \\
e eletricidade & \\
\hline Misturas e substâncias/célula & 01 professor \\
\hline Citologia, histologia, reações químicas e misturas & 01 professor \\
\hline Misturas & 01 professor \\
\hline
\end{tabular}

Fonte: Dados da pesquisa, 2019.

Assim, nossos resultados concordam com Medeiros quando ela salienta que:

\begin{abstract}
Compreendendo que Ciências e Biologia são disciplinas que se fazem entender muito mais quando acompanhadas por modelos concretos, como, por exemplo, no estudo da Fisiologia Humana, tendo acesso físico aos principais órgãos de mamíferos semelhantes aos do homem, como coração, pulmão e rins; Citologia, estudo da célula, com microscópios, lupas e lâminas; Zoologia, com animais conservados e coleções entomológicas, desse modo, facilitando o aprendizado de determinados conceitos. (2018, p. 10)
\end{abstract}

Percebemos a necessidade de um laboratório em uma escola e quanto esse acesso ao concreto permitirá aos alunos uma aprendizagem mais eficaz; aos docentes, uma forma de expressar o conteúdo além da teoria; e o quanto a falta dessas práticas pode estar prejudicando a aprendizagem dos discentes.

Todos os docentes entrevistados consideram de muita importância as aulas práticas em um laboratório; 23 dizem que os alunos se sentem estimulados quando estão assistindo a alguma aula prática e todos disseram acreditar que o processo de ensino e aprendizagem de $\mathrm{CN}$ ocorre de maneira mais eficaz quando relaciona a teoria com a prática. Podemos afirmar, portanto, que realizar aulas práticas é de suma importância para esses professores e que a 
execução desses experimentos contribuirá de forma positiva para o ensino e a aprendizagem dos estudantes (ROSITO, 2008, p. 197):

\begin{abstract}
A experimentação é essencial para um bom ensino de ciências. Em parte, isso se deve ao fato de que o uso de atividades práticas permite maior interação entre o professor e os alunos, proporcionando, em muitas ocasiões, a oportunidade de um planejamento conjunto e o uso de estratégias de ensino que podem levar a melhor compreensão dos processos das ciências.
\end{abstract}

Essa estratégia desperta nos alunos interesse pelo conteúdo e uma melhor relação entre os envolvidos na troca de conhecimento, e "também pode ser utilizada para poupar tempo, quando o professor dispõe de poucos materiais para toda a turma e é uma forma de toda a turma observar o fenômeno ao mesmo tempo" (ROSSASI; POLINARSKI, 2015, p.10). Juntamente com a aula expositiva, essas práticas se tornam uma metodologia que visa a contribuir para o ensino e a aprendizagem dos alunos.

\title{
6 Considerações finais
}

A utilização de laboratórios pelos professores de CN no ensino fundamental - anos finais está relacionada com a formação acadêmica desses docentes, o demonstra a importância da realização de aulas práticas durante a formação. Foi possível obter um panorama geral sobre a percepção dos professores de $\mathrm{CN}$ sobre sua própria formação, a estrutura física das escolas e a importância das aulas práticas para o ensino de Ciências. Assim, pôde-se observar que, nos municípios de Abaiara, Brejo Santo e Milagres, o professor, mesmo sendo formado na área de $\mathrm{CN}$, não considera sua formação suficiente para conduzir aulas práticas de laboratório no ensino básico, sinalizando, dessa forma, a relevância que os cursos de licenciatura estão atribuindo à formação prática dos professores dentro das Ciências.

Afirma-se também que há uma grande discrepância em termos estruturais para aulas práticas nas escolas do ensino fundamental - anos finais. Mesmo as escolas de áreas urbanas apresentam pouca estrutura, e aquelas das zonas rurais não contam com algum espaço físico semelhante a um laboratório de CN. Além disso, percebeu-se uma falta de incentivo para utilização de aulas práticas por parte da gestão escolar. Observa-se que instituições formadoras dos cursos de licenciatura devem se estruturar com vistas a melhor preparar os 
futuros professores para a utilização dos laboratórios em aulas práticas. Ao mesmo tempo, devem prepará-los para desenvolverem, da melhor forma possível, atividades práticas nas escolas que não têm essa estrutura, tendo em vista que a sua falta é a regra na maioria das escolas.

Um conjunto de providências é necessário, então, tanto no campo de formação prática dos professores, como em termos de concepção de estrutura física de laboratórios e de equipamentos para que o ensino de $\mathrm{CN}$ realmente atinja os objetivos a que se propõe. Também são necessários novos estudos acerca do uso de laboratórios no ensino médio abrangendo os municípios em questão.

\section{Referências}

AFONSO, M. A.; BONAPAZ, L. S.; SEVERO. M. V. Contribuições de aulas práticas no aprendizado do ensino em Biologia para os alunos de uma escola de Santa Rosa /RS, 2014. Disponível em:

https://semanaacademica.org.br/system/files/artigos/marcos_ultima_correcao1.pdf. Acesso em: 28 dez. 2018.

ANDRADE, T. Y. I.; COSTA. M. B. O Laboratório de Ciências e a Realidade dos Docentes das Escolas Estaduais de São Carlos-SP. Quím. Nova Esc. - São Paulo-SP. v. 38, n. 3, p. 208-214, ago. 2016. Disponível em: http://qnesc.sbq.org.br/online/qnesc38_3/04-EA-0615.pdf. Acesso em: 30 dez. 2018.

ASSOLINI, E. Professor sem formação específica, problema a ser solucionado. Jornal da USP. 03 fev. 2017. Disponível em: https://jornal.usp.br/atualidades/professor-sem-formacaoespecifica-problema-a-ser-solucionado/. Acesso em: 29 maio 2019.

BRASIL, M. E. Base nacional comum curricular: a área de ciências da natureza. Disponível em:

http://basenacionalcomum.mec.gov.br/images/BNCC_EI_EF_110518_versaofinal_site.pdf. Acesso em: 25 jun. 2019.

BEREZUK, P. A.; INADA, P. Avaliação dos laboratórios de ciências e Biologia das escolas públicas e particulares de Maringá, Estado do Paraná. Acta Scientiarum. Human and Social Sciences, v. 32, n. 2, 2010, p. 207-215. Disponível em:

http://www.redalyc.org/pdf/3073/307325336011.pdf. Acesso em: 09 jun. 2019.

BEREZUK, P. A. Concepções e práticas de professores de ciências em relação ao trabalho prático, experimental, laboratorial e de campo. 2009. 145 f. Dissertação (Mestrado em Educação para a Ciência e o Ensino de Matemática) - Universidade Estadual de Maringá. Disponível em:

http://repositorio.uem.br:8080/jspui/bitstream/1/4425/1/000180936.pdf. Acesso em: 20 jun 2019. 
CRUZ, J. B. Laboratórios. Brasília: Universidade de Brasília, 2007. Disponível em: http://portal.mec.gov.br/seb/arquivos/pdf/profunc/13_laboratorios.pdf. Acesso em: 10 fev. 2019.

DAMASCENO, P. S. A importância das aulas de laboratório nas diversas áreas da Ciência: o desenvolvimento de competências. Disponível em: http://educacao.estadao.com.br/blogs/colegio-pentagono-importancia-das-aulas-de-laboratório -nas-diversas-areas-da-ciencia-o-desenvolvimento-de-competencias/. Acesso em: 20 jan. 2019.

CHIZZOTTI, A. Pesquisa em ciências humanas e sociais. 11. ed. São Paulo: Cortez. 2014. Parte II, Cap.2.

FURMAN, M. O ensino de Ciências no Ensino Fundamental: colocando as pedras fundacionais do pensamento científico. 2009. Disponível em: http://www.famesc.edu.br/biblioteca/biblioteca/ebooks/O\%20ensino\%20de\%20Ci\%C3\%AAn cias\%20NO\%20ENSINO\%20FUNDAMENTAL.pdf. Acesso em: 10 jan. 2019.

GAVETTI, S. M. V. C. Guia para utilização de laboratórios químico e biológicos. Universidade Estadual Paulista "Júlio Mesquita Filho", Campus de Sorocaba, 2013. Disponível em: https://www.sorocaba.unesp.br/Home/CIPA/Treinamento_para_utilizacao_de_laboratorios_q uimicos_e_biologicos_leitura.pdf. Acesso em: 9 jul. 2019.

KRASILCHIK, M. Prática no ensino de Biologia.4. ed. São Paulo: Editora da Universidade da São Paulo. 2008.

KOREN, T.; BERTOLDO, R. R. Otimização do laboratório de ciências. Cadernos PDE. V.1, Paraná, Brasil. 2013. Disponível em:

http://www.diaadiaeducacao.pr.gov.br/portals/cadernospde/pdebusca/producoes_pde/2013/20 13_unioeste_qui_artigo_tercilo_koren.pdf. Acesso em: 8 jun. 2019.

MARANDINO, M. A experimentação científica e o ensino experimental em Ciências e Biologia. In: MARANDINO, M.; SELLES, S. E.; FERREIRA, M. S. (org.) Ensino de Biologia: histórias e práticas em diferentes espaços formativos. São Paulo: Cortez, 2009.

MEDEIROS, O. K. C. Reflexões sobre a revitalização de um laboratório de ciências: materiais didáticos e roteiros práticos. 2018. 220 f. Dissertação (Mestrado Profissional em Ensino de Ciências e Matemática) - Universidade Federal de Uberlândia, Uberlândia, 2018. Disponível em: http://dx.doi.org/10.14393/ufu.di.2018.553. Acesso em: 12 jun. 2019.

MELLO, G. N. Formação inicial de professores para a educação básica uma (re)visão radical. São Paulo Perspectiva. v.14, n. 1, jan./mar. 2000. DOI: https://doi.org/10.1590/S010288392000000100012. Disponível em: https://www.scielo.br/scielo.php?pid=S0102$88392000000100012 \&$ script=sci_abstract. Acesso em: 10 mar. 2019.

PIERSON, A. H. C.; NEVES, M. R. Interdisciplinaridade na formação de professores de ciências: conhecendo obstáculos. Revista Brasileira de Pesquisa em Educação de Ciências. v. 1, n. 2, maio/ago. 2001. Disponível em: https://periodicos.ufmg.br/index.php/rbpec/article/view/4168/2733. Acesso em: 12 jan. 2019. 
PONTILI, R. M.; KASSOUF, A. L. Fatores que afetam a frequência e o atraso escolar, nos meios urbano e rural, de São Paulo e Pernambuco. Revista de Economia e Sociologia Rural, v. 45, n. 1, jan./mar. 2007. Disponível em: http://www.scielo.br/pdf/resr/v45n1/02.pdf. Acesso em: 12 jun. 2019.

RODRIGUES, B. A.; BORGES, A. T. O ensino de ciências por investigação: reconstrução histórica. In: XI ENCONTRO DE PESQUISA EM ENSINO DE FÍSICA, Curitiba, 2008. Anais [...]. Curitiba, 2008. Disponível em: http://www.contagem.mg.gov.br/arquivos/comunicacao/femcitec_ensinodeciencia06.pdf. Acesso em: 16 jun. 2019.

ROSITO, B. A. O ensino de Ciências e a experimentação. In: MORAES, R. (org.). Construtivismo e ensino de ciências: Reflexões epistemológicas e metodológicas. 3. ed. Porto Alegre: EDIPUCRS, 2008. p.195-208.

ROSSASI, L. B.; POLINARSKI, C. A. Reflexões sobre metodologias para o ensino de Biologia: uma perspectiva a partir da prática docente, 2015. Disponível em: http://www.diaadiaeducacao.pr.gov.br/portals/pde/arquivos/491-4.pdf. Acesso em: 1 fev. 2019.

SANTOS, A. F.; PAIVA, G.E.R.; SANTOS, M.L.A.; RODRIGUES, E.S. Formação de professores e o não uso do laboratório de Física: um estudo de caso. Revista Eletrônica da Fainor, Vitória da Conquista, v. 9, n. 2, p. 220-238, jul./dez. 2016.

SOARES, L. G. Desafios dos alunos de classes menos favorecidas para ingressar e permanecer na universidade. Revista Extensão \& Cidadania, v. 2, n. 4, p.120-136, 2014.

SOUZA, E. R.; ONAKA, N.K.C.O. Programas institucionais e a formação docente. In: XXII ENCONTRO NACIONAL DE EDUCAÇÃO, EDUCERE, 2015, Curitiba. Anais [...]. Curitiba, 2015. Disponível em: https://educere.bruc.com.br/arquivo/pdf2015/17140_9406.pdf. Acesso em: 29 maio 2019.

SOUZA, S. E. O uso de recursos didáticos no ensino escolar. I Encontro de Pesquisa em Educação. Arq. Mudi, 11 (Supl. 2), p. 10-14, 2007. Disponível em: http://www.dma.ufv.br/downloads/MAT\%20103/2015-II/slides/Rec\%20Didaticos\%20\%20MAT\%20103\%20-\%202015-II.pdf. Acesso em: 1 jun. 2019.

VIÉGAS, A. L. D. C.; CRUZ, L. M. D. C.; MENDES, A. P. F. T. Formação de Professores em Ciências Biológicas: desafios, limites e possibilidades. UNOPAR Cient., Ciência Humana e Educação, Londrina, v. 16, n. 5, p. 507-519, 2015. Disponível em: http://revista.pgsskroton.com.br/index.php/ensino/article/viewFile/3866/3219. Acesso_em: 22 maio 2019.

VILLANI, A.; PACCA, J. L. A. Construtivismo, conhecimento científico e habilidade didática no ensino de ciências. Revista da Faculdade de Educação, São Paulo, v. 23, n. 1-2, jan./dez. 1997.

YAMAZAKI, S. C.; YAMAZAKI, R. M. O. Sobre o uso de metodologias alternativas para ensino-aprendizagem de ciências. 2006. Disponível em: encurtador.com.br/mEHWY.

Acesso em: 10 jun. 2019. 
Silva, E. F. da; FERREIRA, R. N. C.; SOUZA, E. de J.

Enviado em: 22/08/2020

Revisado em: 17/02/2021

Aprovado em: 01/03/2021

Publicado em: 15/06/2021 